\title{
Hematopoietic Microenvironment in the Fetal Liver: Roles of Different Cell Populations
}

\author{
Olga V. Payushina \\ Koltzov Institute of Developmental Biology, Russian Academy of Sciences, 26 Vavilov Street, Moscow 119334, Russia \\ Correspondence should be addressed to Olga V. Payushina, payushina@mail.ru \\ Received 10 September 2012; Accepted 2 October 2012 \\ Academic Editors: E. Meacci, A. A. Minin, and C. C. Uphoff \\ Copyright () 2012 Olga V. Payushina. This is an open access article distributed under the Creative Commons Attribution License, \\ which permits unrestricted use, distribution, and reproduction in any medium, provided the original work is properly cited.
}

Hematopoiesis is the main function of the liver during a considerable period of mammalian prenatal development. Hematopoietic cells of the fetal liver exist in a specific microenvironment that controls their proliferation and differentiation. This microenvironment is created by different cell populations, including epitheliocytes, macrophages, various stromal elements (hepatic stellate cells, fibroblasts, myofibroblasts, vascular smooth muscle and endothelial cells, mesenchymal stromal cells), and also cells undergoing epithelial-to-mesenchymal transition. This paper considers the involvement of these cell types in the regulation of fetal liver hematopoiesis.

\section{Introduction}

In mammals, the liver serves as the main hematopoietic organ during a considerable period of prenatal ontogeny. In murine liver, for example, hematopoietic cells first appear in 10-day embryos, with hematopoietic function of the organ reaching a peak on embryonic days 13-14 and ceasing during the first 2-4 postnatal days $[1,2]$. Hematopoiesis requires specific microenvironment that produces chemical signals to attract hematopoietic cells and regulates their proliferation and differentiation via contact and humoral interactions. The hematopoietic microenvironment of the fetal liver is created by a complex of cell types, including epitheliocytes, resident macrophages, and several stromal cell populations of mesenchymal origin such as hepatic stellate cells, fibroblasts, myofibroblasts, vascular smooth muscle and endothelial cells, and mesenchymal stromal cells (MSCs). Let us consider the roles of different cell components of this microenvironment in the maintenance of hematopoietic activity in the developing liver.

\section{Liver Epithelium}

At early stages of liver development, its epithelium is represented by bipotent hepatoblasts, which subsequently differentiate into hepatocytes and cholangiocytes [1,2]. Hepatoblasts can be identified by the simultaneous expression of both hepatic (cytokeratin 18, albumin) and biliary epithelial markers (cytokeratin 19) and also of E-cadherin [3]. The morphology and phenotype of liver epithelial cells change in the course of development, and these changes correlate with hematopoietic activity $[4,5]$. Cells of the hepatocyte lineage appear to play an important role in the regulation of erythropoiesis: they closely interact with erythroblasts [5] and produce erythropoietic cytokines such as stem cell factor and erythropoietin $[6,7]$.

Localization of megakaryocyte lineage cells among hepatocytes described in human fetal liver [8] and thrombopoietin production by some lines of murine hepatocytes [9] both suggest a contribution of the hepatic epithelium to the control of megakaryocytopoiesis.

The involvement of the epithelium in maintaining the hematopoietic function of the liver is confirmed by the existence of hepatoblast and hepatocyte cell lines capable of supporting hematopoiesis in long-term culture via secretion of cytokines [9] or adhesive interactions with hematopoietic progenitor cells [10]. The biliary epithelium can also support both long-term proliferation of hematopoietic cells and production of committed erythroid or granulocyte/macrophage 
progenitors by means of contact interactions via liverregulating protein that is expressed on the surface of the epitheliocytes [11].

\section{Macrophages}

In the developing liver, macrophages first appear in sinusoids. At the stage of active liver hematopoiesis, they migrate to the parenchyma to form erythroblastic islands consisting of a central macrophage surrounded by erythroblasts and sparse lymphocytes $[12,13]$. The interaction of erythroid cells with macrophages mediated by the erythroblast macrophage protein (Emp) is necessary for their enucleation [14]. Moreover, macrophages express vascular cell adhesion molecule VCAM-1, which also mediates their adhesive interactions with erythroblasts [15], and jagged-1, a ligand for the Notch signal system involved in regulation of hematopoiesis [13]. The central macrophages of erythroblastic islands degenerate as hematopoiesis in the liver ceases [12].

Another population of macrophages in the fetal liver consists of Kupffer cells, which line the sinusoids. Some recent findings suggest that they derive from the yolk sac and are not a progeny of definitive hematopoietic stem cells [16]. Their functions in the maintenance of hematopoiesis consist in phagocytosis of the nuclei extruded from late-stage erythroblasts [17, 18] and secretion of erythropoietin [19]. The presence of dividing and maturing erythroblasts in the vacuoles of Kupffer cells, which has been observed in the fetal liver [18], may also indicate the role of these cells in the regulation of erythropoiesis.

\section{Hepatic Stellate Cells}

The hepatic stellate cells, or Ito cells, are located in the perisinusoidal space of Disse. Quiescent stellate cells contain retinoid lipid droplets. When activated, they lose these droplets and acquire morphological and phenotypic feature characteristics of myofibroblasts, including the expression of smooth muscle actin [20]. Activation of stellate cells occurs upon liver damage $[21,22]$. They also become activated in monolayer cultures but remain quiescent when cultured on collagen gel [21].

The stellate cells of the fetal liver express desmin $[23,24]$, $\beta 3$-integrin, nestin [24], CRBP-1 [25], N-CAM [26], and reelin [27]. Some researchers consider that these cells are derived from mesenchymal cells of septum transversum, which form the submesothelial layer under the liver capsule $[26,28,29]$, but their epithelial origin cannot be excluded [30]. The number of hepatic stellate cells increases in the course of development [25]. In the fetal period, they are associated with hematopoietic cells [23] and apparently regulate hematopoiesis by secreting chemoattractants (such as stromal cell-derived factor-1) as well as by means of contact interactions mediated by VCAM-1 [24]. Hepatic stellate cells are also known to secrete erythropoietin [6] and stem cell factor [31]. Therefore, these cells can be regarded as an important component of the hematopoietic microenvironment.

\section{Fibroblasts and Myofibroblasts}

In either adult or fetal liver, fibroblasts (myofibroblasts) are located in the region of portal triads $[20,25]$, around central veins, and in the Glisson capsule [22] or, in the fetal liver, in the submesothelial layer of mesenchymal cells [29]. Portal myofibroblasts express smooth muscle actin and desmin and are morphologically similar to activated stellate cells [20,32]. However, they are not related by origin to hepatic stellate cells [19, 32]; unlike the latter, they express CD90 [32, 33], gremlin [33], fibulin-2, and interleukin-6 [34] but do not express reelin [35].

Perivascular fibroblasts of the fetal liver are cells of mesodermal origin [29]. All stromal cells of portal triads at early developmental stages express smooth muscle actin, but they are subsequently substituted by fibroblasts characteristically expressing vimentin (but not smooth muscle actin) [25]. Thus, myofibroblasts disappear during development and are absent in the normal adult liver [22].

Morphological and immunohistochemical analysis of fetal liver reveals myelopoiesis mainly around the blood vessels, that is, in places where the fibroblasts and myofibroblasts are located $[8,36]$. These findings may reflect their important role in the regulation of myeloid differentiation. However, the role of myofibroblasts and fibroblasts in the regulation of hematopoiesis has not been studied sufficiently. Some data suggest their involvement in organizing the hematopoietic microenvironment by producing extracellular matrix components, including fibronectin and collagen [37]. Adhesion to fibronectin appears to stimulate proliferation of both hematopoietic stem/progenitor and erythroid cells $[38,39]$, which is confirmed by correlation between the content of this protein in the periportal region and the activity of hematopoiesis in human fetal liver [40]. In murine fetal liver, myeloid cells are associated with perivascular and subcapsular collagen, that may suggest a significance of its production by stromal cells for supporting myelopoiesis [5].

\section{Myoid Cells}

Differentiated smooth muscle cells in the human fetal liver have been found only in the tunica media of hepatic artery branches [25]. However, the fetal mouse liver has served as the source of numerous stromal cell lines expressing markers of different stages of smooth muscle cell differentiation. Many of these lines, especially those at early or middle differentiation stages, can maintain hematopoiesis in longterm culture and probably correspond to pericytes located around venous capillaries [41, 42]. Immature cells of this lineage are likely to produce hematopoietic cytokines, as it has been shown for myoid cells of bone marrow stroma [43], whereas more mature (contractile) cells may control migration of hematopoietic cells by modifying the permeability of intercellular spaces between endotheliocytes [42].

Unexpectedly, the fetal liver in different species has proved to contain precursor cells of skeletal muscles showing spontaneous fusion into myotubes in vitro [44-46]. These cells may enter the liver and other organs of the embryo when they migrate from the dermomyotome to populate 
areas where skeletal muscles are to be formed. However, in view of the data that skeletal myoblasts secrete a wide range of regulatory molecules, including stromal cell-derived factor1 and hematopoietic cytokines such as macrophage colonystimulating factor [47], their specific role in the maintenance of liver hematopoiesis cannot be excluded.

\section{Vascular Endothelium}

The endothelium of blood vessels in different parts of fetal liver acini differs in structure: it forms a continuous layer in portal vessels but is fenestrated in central veins [48]. Regarding the hematopoietic function of the liver, of special interest is the endothelium of sinusoids, which mature blood cells must penetrate to enter the circulation. The sinusoids at early stages of development are lined with a continuous endothelium, but its structure subsequently changes so that it becomes highly permeable to blood cells and regulatory molecules. The basal membrane disappears, composition of the extracellular matrix changes [49], and diaphragmed or open fenestrae, intercellular fissures, and temporary migration pores are formed $[17,48]$. The porosity of the sinusoidal endothelium decreases by the end of prenatal ontogeny, when its structure and phenotype approach those in the adult liver $[48,49]$.

Due to the expression of cell adhesion molecules such as E-selectin and VCAM-1 [50, 51] and chemoattractants such as stromal cell-derived factor-1 [52], the sinusoidal endothelium in the fetal liver can control the homing of hematopoietic cells, their retention in the niche, and release into the circulation. In the fetal liver, hematopoietic stem cells interact with the sinusoidal endothelium via activated protein C. This interaction facilitates self-renewal of the stem cells and prevents their apoptosis [53]. Moreover, endothelial cell lines or medium conditioned by them maintain in vitro differentiation of erythroid and granulocytemacrophage lineage cells $[54,55]$, which is evidence for the ability of endotheliocytes to regulate hematopoiesis via contact interactions with hematopoietic cells and secretion of cytokines. Fetal liver endothelial cells can also promote Blymphopoiesis from primitive hematopoietic cells [51].

\section{Mesenchymal Stromal Cells (MSCs)}

Multipotent MSCs are plastic-adhesive cells with a specific antigenic phenotype (for human cells, CD105 ${ }^{+} \mathrm{CD}^{+} 3^{+}$ $\mathrm{CD}^{+}{ }^{+} \mathrm{CD}_{4}{ }^{-} \mathrm{CD} 34^{-} \mathrm{CD} 14^{-} \mathrm{CD} 11 b^{-} \mathrm{CD}^{-} 9 \mathrm{a}^{-} \mathrm{CD} 19^{-}$ HLA-DR ${ }^{-}$) and potential for osteogenic, adipogenic, and chondrogenic differentiation [56]. They were first identified by Friedenstein et al. [57] in the mouse bone marrow, spleen, and thymus as fibroblast colony-forming units. To date, MSCs have been revealed in many organs (including the fetal liver), where they apparently reside in vascular walls [58]. MSCs of the fetal liver have certain distinctive features, compared to such cells from other organs. Thus, they show higher proliferative activity than MSCs from the adult bone marrow $[59,60]$, but their osteogenic and adipogenic potential is lower [61]. With respect to osteogenic capacity, they are also inferior to MSCs from other fetal organs $[62,63]$.
In the course of embryonic development, MSC supposedly migrate to the liver from the aortic-gonad-mesonephros region [64], although their de novo formation from the septum transversum mesenchyme is also possible. The amount of these cells in the liver changes during development in correlation with hematopoietic activity [65-67], which is evidence for their important role in organization of the hematopoietic microenvironment. The cessation of hematopoiesis in the liver is accompanied by a decrease in not only the number of MSCs but also in their proliferative activity [59] and differentiation potential [67].

In the fetal liver, MSCs are a probable source of stromal cells similar in their characteristics to smooth muscle cells [42]; it is also not excluded that they can differentiate into myofibroblasts [68] and endothelial cells [69]. Apparently, the role of these cells is not limited to their differentiation into more specialized components of the hematopoietic stroma. It has been shown for bone marrow MSCs that they can produce stromal cell-derived factor-1 [70], interact with hematopoietic cells via surface molecules (VCAM-1, cadherins, integrins and, etc.), and regulate their proliferation and differentiation by secreting wide range of cytokines $[71,72]$. Such regulatory functions are also likely for MSCs of the fetal liver, although experimental evidence for their ability to maintain hematopoiesis is as yet scarce $[66,73]$.

\section{Epithelial-to-Mesenchymal Transition (EMT)}

In addition to cell populations with distinct epithelial or mesenchymal phenotypic traits, the developing liver contains cells undergoing epithelial-to-mesenchymal transition (EMT), which coexpress mesenchymal markers (e.g., vimentin, N-cadherin, Stro-1, osteopontin, collagen type I, smooth muscle actin), and markers of the liver epithelium (alpha-fetoprotein, cytokeratins 7, 8, and 18, albumin, Ecadherin) [74-76]. The apparent sources of these cells are liver mesenchyme and parenchyma; their origin from hematopoietic stem cells or pluripotent progenitor cells is less probable [74]. In particular, coexpression of epithelial and mesenchymal markers has been described in periportal liver cells [77], stellate cells [30], and hepatic stem cells [76].

Numerous EMT cells are found in the liver at the stage of active hematopoiesis, but they gradually disappear during late prenatal development and are scarce or absent in adult liver $[74,76]$. They are regarded as an important component of the hematopoietic microenvironment. Thus, cells with the EMT phenotype maintain the undifferentiated state of hematopoietic stem cells in vitro [75], and the hematopoietic supportive ability of EMT clonal cell line AFT024 is lost after its hepatocytic differentiation induced by oncostatin M [74]. A noteworthy fact is that a major regulatory role is attributed to fibronectin production by cells of portal triads, which have certain traits of EMT [77].

\section{Stromal Regulation of Hepatogenesis}

Hematopoiesis in the fetal liver is coincident with histogenesis of its epithelial tissue. Available data indicate that 
the stromal cell populations described above take part in the regulation of hepatogenesis as well as of hematopoiesis. In particular, there is evidence for secretion of hepatocyte growth factor by hepatic stellate cells [24], periportal connective tissue cells, and endothelial cells of the fetal liver [78] and for stimulation of the survival and proliferation of hepatic stem cells by stellate cells [79] or endotheliocytes [80] in cocultures. Paracrine signals from stellate cells stimulate hepatocytic differentiation in vitro [81], and co-culturing of hepatocytes with a certain fibroblast population induces them to form hepatic cordlike structures [82]. There is also evidence that the interaction of portal myofibroblasts and epithelium is important for the development of intrahepatic bile ducts [83]. Moreover, hematopoietic cells also affect hepatogenesis through the production of oncostatin $M$ that stimulates the functional maturation of hepatocytes [84].

By conclusion, the hematopoietic microenvironment in the fetal liver is created by a complex of different epithelial and mesenchymal cell types. They produce cytokines, chemoattractants, extracellular matrix components, and so forth. and directly interact with hematopoietic cells, thereby providing for the functioning of the liver as a hematopoietic organ during a considerable period of prenatal development. To date, the niche for hematopoietic stem cells in the fetal liver has been characterized in sufficient detail, but further studies are needed to gain a deeper insight into the roles of different cell populations in the regulation of hematopoietic and hepatocyte differentiation.

\section{Abbreviations}

MSCs: Mesenchymal stromal cells

EMT: Epithelial-to-mesenchymal transition.

\section{Acknowledgments}

The work was supported by the Russian Foundation for Basic Research, Project no. 11-04-00011a. The author thanks Dr. Nikolay A. Gorgolyuk for providing language help.

\section{References}

[1] K. Sasaki and Y. Sonoda, "Histometrical and three-dimensional analyses of liver hematopoiesis in the mouse embryo," Archives of Histology and Cytology, vol. 63, no. 2, pp. 137-146, 2000.

[2] Y. Guo, X. Zhang, J. Huang et al., "Relationships between hematopoiesis and hepatogenesis in the midtrimester fetal liver characterized by dynamic transcriptomic and proteomic profiles," PLoS ONE, vol. 4, no. 10, article e7641s, 2009.

[3] J. D. Terrace, I. S. Currie, D. C. Hay et al., "Progenitor cell characterization and location in the developing human liver," Stem Cells and Development, vol. 16, no. 5, pp. 771-778, 2007.

[4] T. Fukumoto, "Possible developmental interactions of hematopoietic cells and hepatocytes in fetal rat liver," Biomedical Research, vol. 13, no. 6, pp. 385-413, 1992.

[5] J. D. P. Ayres-Silva, P. P. D. A. Manso, M. R. D. C. Madeira, M. Pelajo-Machado, and H. L. Lenzi, "Sequential morphological characteristics of murine fetal liver hematopoietic microenvironment in Swiss Webster mice," Cell and Tissue Research, vol. 344, no. 3, pp. 455-469, 2011.

[6] K. U. Eckardt, "Erythropoietin production in liver and kidneys," Current Opinion in Nephrology and Hypertension, vol. 5, pp. 28-34, 1996.

[7] D. Sugiyama, K. Kulkeaw, C. Mizuochi, Y. Horio, and S. Okayama, "Hepatoblasts comprise a niche for fetal liver erythropoiesis through cytokine production," Biochemical and Biophysical Research Communications, vol. 410, no. 2, pp. 301306, 2011.

[8] I. Emura, M. Sekiya, and Y. Ohnishi, "Ultrastructural identification of the hemopoietic inductive microenvironment in the human embryonic liver," Archivum Histologicum Japonicum, vol. 47, no. 1, pp. 95-112, 1984.

[9] A. Aiuti, C. Cicchini, S. Bernardini et al., "Hematopoietic support and cytokine expression of murine-stable hepatocyte cell lines (MMH)," Hepatology, vol. 28, no. 6, pp. 1645-1654, 1998.

[10] M. Nanno, M. Hata, H. Doi et al., "Stimulation of in vitro hematopoiesis by a murine fetal hepatocyte clone through cellcell contact," Journal of Cellular Physiology, vol. 160, no. 3, pp. 445-454, 1994.

[11] A. Corlu, I. Lamy, G. P. Ilyin et al., "Hematopoiesis-promoting activity of rat liver biliary epithelial cells: Involvement of a cell surface molecule, liver-regulating protein," Experimental Hematology, vol. 26, no. 5, pp. 382-394, 1998.

[12] K. Sasaki and H. Iwatsuki, "Origin and fate of the central macrophages of erythroblastic islands in the fetal and neonatal mouse liver," Microscopy Research and Technique, vol. 39, no. 5, pp. 398-405, 1997.

[13] D. Li, G. Y. Wang, Z. F. Liu, Y. X. Shi, H. Zhang, and Z. L. Bai, "Macrophage-associated erythropoiesis and lymphocytopoiesis in mouse fetal liver: ultrastructural and ISH analysis," Cell Biology International, vol. 28, no. 6, pp. 457-461, 2004.

[14] S. Soni, S. Bala, B. Gwynn, K. E. Sahr, L. L. Peters, and M. Hanspal, "Absence of erythroblast macrophage protein (Emp) leads to failure of erythroblast nuclear extrusion," Journal of Biological Chemistry, vol. 281, no. 29, pp. 20181-20189, 2006.

[15] J. Isern, S. T. Fraser, Z. He, and M. H. Baron, "The fetal liver is a niche for maturation of primitive erythroid cells," Proceedings of the National Academy of Sciences of the United States of America, vol. 105, no. 18, pp. 6662-6667, 2008.

[16] C. Schulz, E. Gomez Perdiguero, L. Chorro et al., "A lineage of myeloid cells independent of Myb and hematopoietic stem cells," Science, vol. 336, pp. 86-90, 2012.

[17] P. W. Bankston and R. M. Pino, "The development of the sinusoids of fetal rat liver: morphology of endothelial cells, Kupffer cells, and the transmural migration of blood cells into the sinusoids," American Journal of Anatomy, vol. 159, no. 1, pp. $1-15,1980$.

[18] W. B. Lee, S. K. Erm, K. Y. Kim, and R. P. Becker, "Emperipolesis of erythroblasts within Kupffer cells during hepatic hemopoiesis in human fetus," The Anatomical Record, vol. 256, pp. 158-164, 1999.

[19] P. Paul, S. A. Rothmann, J. T. McMahon, and A. S. Gordon, "Erythropoietin secretion by isolated rat Kupffer cells," Experimental Hematology, vol. 12, no. 11, pp. 825-830, 1984.

[20] G. Ramadori and B. Saile, "Mesenchymal cells in the liverone cell type or two?” Liver, vol. 22, no. 4, pp. 283-294, 2002.

[21] M. Sato, S. Suzuki, and H. Senoo, "Hepatic stellate cells: unique characteristics in cell biology and phenotype," Cell Structure and Function, vol. 28, no. 2, pp. 105-112, 2003. 
[22] C. Guyot, S. Lepreux, C. Combe et al., "Hepatic fibrosis and cirrhosis: the (myo)fibroblastic cell subpopulations involved," International Journal of Biochemistry and Cell Biology, vol. 38, no. 2, pp. 135-151, 2006.

[23] A. P. Kiassov, P. Van Eyken, J. F. Van Pelt et al., "Desmin expressing nonhematopoietic liver cells during rat liver development: an immunohistochemical and morphometric study," Differentiation, vol. 59, no. 4, pp. 253-258, 1995.

[24] H. Kubota, H. L. Yao, and L. M. Reid, "Identification and characterization of vitamin A-storing cells in fetal liver: implications for functional importance of hepatic stellate cells in liver development and hematopoiesis," Stem Cells, vol. 25, no. 9, pp. 2339-2349, 2007.

[25] J. Villeneuve, F. Pelluard-Nehme, C. Combe et al., "Immunohistochemical study of the phenotypic change of the mesenchymal cells during portal tract maturation in normal and fibrous (ductal plate malformation) fetal liver," Comparative Hepatology, vol. 8, article 5, 2009.

[26] C. K. C. Loo and X. J. Wu, "Origin of stellate cells from submesothelial cells in a developing human liver," Liver International, vol. 28 , no. 10, pp. 1437-1445, 2008.

[27] B. Samama and N. Boehm, "Reelin immunoreactivity in lymphatics and liver during development and adult life," The Anatomical Record A, vol. 285, pp. 595-599, 2005.

[28] H. Enzan, H. Himeno, M. Hiroi, H. Kiyoku, T. Saibara, and S. Onishi, "Development of hepatic sinusoidal structure with special reference to the Ito cells," Microscopy Research and Technique, vol. 39, pp. 336-349, 1997.

[29] K. Asahina, S. Y. Tsai, P. Li et al., "Mesenchymal origin of hepatic stellate cells, submesothelial cells, and perivascular mesenchymal cells during mouse liver development," Нераtology, vol. 49, no. 3, pp. 998-1011, 2009.

[30] Y. S. Lim, K. A. Kim, J. O. Jung et al., "Modulation of cytokeratin expression during in vitro cultivation of human hepatic stellate cells: evidence of transdifferentiation from epithelial to mesenchymal phenotype," Histochemistry and Cell Biology, vol. 118, no. 2, pp. 127-136, 2002.

[31] K. Fujio, R. P. Evarts, Z. Hu, E. R. Marsden, and S. S. Thorgeirsson, "Expression of stem cell factor and its receptor, c-kit, during liver regeneration from putative stem cells in adult rat," Laboratory Investigation, vol. 70, no. 4, pp. 511-516, 1994.

[32] J. Dudas, T. Mansuroglu, D. Batusic, B. Saile, and G. Ramadori, "Thy-1 is an in vivo and in vitro marker of liver myofibroblasts," Cell and Tissue Research, vol. 329, no. 3, pp. 503-514, 2007.

[33] J. Dudas, T. Mansuroglu, D. Batusic, and G. Ramadori, “Thy-1 is expressed in myofibroblasts but not found in hepatic stellate cells following liver injury," Histochemistry and cell biology, vol. 131, no. 1, pp. 115-127, 2009.

[34] T. Knittel, D. Kobold, B. Salle et al., "Rat liver myofibroblasts and hepatic stellate cells: different cell populations of the fibroblast lineage with fibrogenic potential," Gastroenterology, vol. 117, no. 5, pp. 1205-1221, 1999.

[35] D. Kobold, A. Grundmann, F. Piscaglia et al., "Expression of reelin in hepatic stellate cells and during hepatic tissue repair: a novel marker for the differentiation of HSC from other liver myofibroblasts," Journal of Hepatology, vol. 36, no. 5, pp. 607$613,2002$.

[36] W. Timens and W. A. Kamps, "Hemopoiesis in human fetal and embryonic liver," Microscopy Research and Technique, vol. 39, pp. 387-397, 1997.
[37] P. S. Amenta and D. Harrison, "Expression and potential role of the extracellular matrix in hepatic ontogenesis: a review," Microscopy Research and Technique, vol. 39, pp. 372-386, 1997.

[38] R. Weinstein, M. A. Riordan, K. Wenc, S. Kreczko, M. Zhou, and N. Dainiak, "Dual role of fibronectin in hematopoietic differentiation,” Blood, vol. 73, no. 1, pp. 111-116, 1989.

[39] T. Yokota, K. Oritani, H. Mitsui et al., "Growth-supporting activities of fibronectin on hematopoietic stem/progenitor cells in vitro and in vivo: structural requirement for fibronectin activities of CS1 and cell-binding domains," Blood, vol. 91, no. 9, pp. 3263-3272, 1998.

[40] D. Tamiolakis, I. Venizelos, S. Nikolaidou, and T. Jivanakis, "Normal development of fetal hepatic haematopoiesis during the second trimester of gestation is upregulated by fibronectin expression in the stromal cells of the portal triads," Revista Espanola de Enfermedades Digestivas, vol. 99, no. 10, pp. 576580, 2007.

[41] P. Charbord, J. P. Rémy-Martin, E. Tamayo, G. Bernard, A. Keating, and B. Péault, "Analysis of the microenvironment necessary for engraftment: role of the vascular smooth musclelike stromal cells," Journal of Hematotherapy and Stem Cell Research, vol. 9, no. 6, pp. 935-943, 2000.

[42] J. E. Dennis and P. Charbord, "Origin and differentiation of human and murine stroma," Stem Cells, vol. 20, no. 3, pp. 205$214,2002$.

[43] L. Sensebe, M. Deschaseaux, J. Li, P. Herve, and P. Charbord, "The broad spectrum of cytokine gene expression by myoid cells from the human marrow microenvironment," Stem Cells, vol. 15, no. 2, pp. 133-143, 1997.

[44] J. Gerhart, B. Bast, C. Neely et al., "MyoD-positive myoblasts are present in mature fetal organs lacking skeletal muscle," Journal of Cell Biology, vol. 155, no. 4, pp. 381-391, 2001.

[45] S. N. Gornostaeva, A. A. Rzhaninova, and D. V. Gol'dstein, "Myogenesis in hemopoietic tissue mesenchymal stem cell culture," Bulletin of Experimental Biology and Medicine, vol. 141, no. 4, pp. 493-499, 2006.

[46] O. N. Sheveleva, O. V. Payushina, M. N. Kozhevnikova, N. N. Butorina, and V. I. Starostin, "Spontaneous and induced myogenesis in cell cultures from rat fetal liver," Cell and Tissue Biology, vol. 5, pp. 551-559, 2011.

[47] J. Henningsen, K. T. G. Rigbolt, B. Blagoev, B. K. Pedersen, and I. Kratchmarova, "Dynamics of the skeletal muscle secretome during myoblast differentiation," Molecular and Cellular Proteomics, vol. 9, no. 11, pp. 2482-2496, 2010.

[48] E. Barbera-Guillem, J. M. Arrue, J. Ballesteros, and F. VidalVanaclocha, "Structural changes in endothelial cells of developing rat liver in the transition from fetal to postnatal life," Journal of Ultrastructure and Molecular Structure Research, vol. 97, no. 1-3, pp. 197-206, 1986.

[49] A. Couvelard, J. Y. Scoazec, M. C. Dauge, A. F. Bringuier, F. Potet, and G. Feldmann, "Structural and functional differentiation of sinusoidal endothelial cells during liver organogenesis in humans," Blood, vol. 87, no. 11, pp. 4568-4580, 1996.

[50] K. M. Schweitzer, A. M. Dräger, P. Van Der Valk et al., "Constitutive expression of E-selectin and vascular cell adhesion molecule-1 on endothelial cells of hematopoietic tissues," American Journal of Pathology, vol. 148, no. 1, pp. 165-175, 1996.

[51] O. Wittig, J. Paez-Cortez, and J. E. Cardier, "Liver sinusoidal endothelial cells promote B lymphopoiesis from primitive hematopoietic cells," Stem Cells and Development, vol. 19, no. 3, pp. 341-349, 2010. 
[52] I. Sawitza, C. Kordes, S. Reister, and D. Häussinger, "The niche of stellate cells within rat liver," Hepatology, vol. 50, no. 5, pp. 1617-1624, 2009.

[53] H. Iwasaki, F. Arai, Y. Kubota, M. Dahl, and T. Suda, "Endothelial protein $\mathrm{C}$ receptor-expressing hematopoietic stem cells reside in the perisinusoidal niche in fetal liver," Blood, vol. 116, no. 4, pp. 544-553, 2010.

[54] Q. Li and L. F. Congoto, "Bovine fetal-liver stromal cells support erythroid colony formation: enhancement by insulinlike growth factor II," Experimental Hematology, vol. 23, no. 1, pp. 66-73, 1995.

[55] O. Ohneda and V. L. Bautch, "Murine endothelial cells support fetal liver erythropoiesis and myelopoiesis via distinct interactions," British Journal of Haematology, vol. 98, no. 4, pp. 798-808, 1997.

[56] M. Dominici, K. Le Blanc, I. Mueller et al., "Minimal criteria for defining multipotent mesenchymal stromal cells. The International Society for Cellular Therapy position statement," Cytotherapy, vol. 8, no. 4, pp. 315-317, 2006.

[57] A. J. Friedenstein, U. F. Gorskaja, and N. N. Kulagina, "Fibroblast precursors in normal and irradiated mouse hematopoietic organs," Experimental Hematology, vol. 4, no. 5, pp. 267-274, 1976.

[58] L. da Silva Meirelles, P. C. Chagastelles, and N. B. Nardi, "Mesenchymal stem cells reside in virtually all post-natal organs and tissues," Journal of Cell Science, vol. 119, no. 11, pp. 2204-2213, 2006.

[59] S. R. M. Versele, R. L. Van Den Heuvel, G. E. R. Schoeters, and O. L. J. Vanderborght, "Proliferation activity of stromal stem cells (CFU-f) from hemopoietic organs of pre- and postnatal mice," Radiation Research, vol. 111, no. 2, pp. 185-191, 1987.

[60] P. V. Guillot, C. Gotherstrom, J. Chan, H. Kurata, and N. M. Fisk, "Human first-trimester fetal MSC express pluripotency markers and grow faster and have longer telomeres than adult MSC," Stem Cells, vol. 25, no. 3, pp. 646-654, 2007.

[61] M. N. Kozhevnikova, A. S. Mikaelyan, and V. I. Starostin, "Molecular-genetic and immunophenotypic analysis of antigen profile and osteogenic and adipogenic potentials of mesenchymal stromal cells from fetal liver and adult bone marrow in rats," Cell and Tissue Biology, vol. 3, no. 3, pp. 222-235, 2009.

[62] P. S. In 't Anker, W. A. Noort, S. A. Scherjon et al., "Mesenchymal stem cells in human second-trimester bone marrow, liver, lung, and spleen exhibit a similar immunophenotype but a heterogeneous multilineage differentiation potential," Haematologica, vol. 88, no. 8, pp. 845-852, 2003.

[63] P. V. Guillot, C. De Bari, F. Dell'Accio, H. Kurata, J. Polak, and N. M. Fisk, "Comparative osteogenic transcription profiling of various fetal and adult mesenchymal stem cell sources," Differentiation, vol. 76, no. 9, pp. 946-957, 2008.

[64] X. Y. Wang, Y. Lan, W. Y. He et al., "Identification of mesenchymal stem cells in aorta-gonad-mesonephros and yolk sac of human embryos," Blood, vol. 111, no. 4, pp. 24362443, 2008.

[65] R. L. Van Den Heuvel, S. R. M. Versele, G. E. R. Schoeters, and O. L. J. Vanderborght, "Stromal stem cells (CFU-f) in yolk sac, liver, spleen and bone marrow of pre- and postnatal mice," British Journal of Haematology, vol. 66, no. 1, pp. 15-20, 1987.

[66] O. V. Payushina, E. I. Bueverova, G. P. Satdykova, V. I. Starostin, E. I. Domaratskaya, and N. G. Khrushchov, "Comparative investigation of mesenchymal stem cells isolated from the bone marrow and fetal liver of mouse and rat," Biology Bulletin, vol. 31, no. 6, pp. 546-551, 2004.
[67] O. V. Payushina, N. N. Butorina, T. M. Nikonova, M. N. Kozhevnikova, O. N. Sheveleva, and V. I. Starostin, "Clonal growth and differentiation of mesenchymal stromal cells from rat liver at different stages of embryogenesis," Cell and Tissue Biology, vol. 6, pp. 12-19, 2012.

[68] F. P. Russo, M. R. Alison, B. W. Bigger et al., "The bone marrow functionally contributes to liver fibrosis," Gastroenterology, vol. 130, no. 6, pp. 1807-1821, 2006.

[69] A. S. Krupnick, K. R. Balsara, D. Kreisel et al., "Fetal liver as a source of autologous progenitor cells for perinatal tissue engineering," Tissue Engineering, vol. 10, no. 5-6, pp. 723-735, 2004.

[70] N. Van Overstraeten-Schlögel, Y. Beguin, and A. Gothot, "Role of stromal-derived factor-1 in the hematopoietic-supporting activity of human mesenchymal stem cells," European Journal of Haematology, vol. 76, no. 6, pp. 488-493, 2006.

[71] M. K. Majumdar, M. A. Thiede, J. D. Mosca, M. Moorman, and S. L. Gerson, "Phenotypic and functional comparison of cultures of marrow-derived mesenchymal stem cells (MSCs) and stromal cells," Journal of Cellular Physiology, vol. 176, pp. 57-66, 1998.

[72] W. Wagner, C. Roderburg, F. Wein et al., "Molecular and secretory profiles of human mesenchymal stromal cells and their abilities to maintain primitive hematopoietic progenitors," Stem Cells, vol. 25, no. 10, pp. 2638-2647, 2007.

[73] Y. Hu, L. Y. Zhang, G. J. Ma, X. Y. Jiang, and C. H. Zhao, "Phenotypical and biological characteristics of human fetal marrow and liver mesenchymal stem cells," Zhongguo Shi Yan Xue Ye Xue Za Zhi, vol. 9, pp. 289-293, 2001.

[74] J. Chagraoui, A. Lepage-Noll, A. Anjo, G. Uzan, and P. Charbord, "Fetal liver stroma consists of cells in epithelialto-mesenchymal transition," Blood, vol. 101, no. 8, pp. 29732982, 2003.

[75] H. Zhang, Z. Miao, Z. He, Y. Yang, Y. Wang, and M. Feng, "The existence of epithelial-to-mesenchymal cells with the ability to support hematopoiesis in human fetal liver," Cell Biology International, vol. 29, no. 3, pp. 213-219, 2005.

[76] B. Li, Y. W. Zheng, Y. Sano, and H. Taniguchi, "Evidence for mesenchymal-epithelial transition associated with mouse hepatic stem cell differentiation," PLoS ONE, vol. 6, no. 2, article e17092, 2011.

[77] M. Lambropoulou, D. Tamiolakis, I. Venizelos et al., "Induction of hepatic haematopoiesis with fibronectin expression by EMT stromal cells during the second trimester of development," Clinical and Experimental Medicine, vol. 7, pp. 115121, 2007.

[78] K. S. Ishikawa, T. Masui, K. Ishikawa, and N. Shiojiri, "Immunolocalization of hepatocyte growth factor and its receptor (c-Met) during mouse liver development," Histochemistry and Cell Biology, vol. 116, no. 5, pp. 453-462, 2001.

[79] E. Schmelzer, L. Zhang, A. Bruce et al., "Human hepatic stem cells from fetal and postnatal donors," Journal of Experimental Medicine, vol. 204, no. 8, pp. 1973-1987, 2007.

[80] A. Xiong, T. W. Austin, E. Lagasse et al., "Isolation of human fetal liver progenitors and their enhanced proliferation by three-dimensional coculture with endothelial cells," Tissue Engineering A, vol. 14, no. 6, pp. 995-1006, 2008.

[81] H. Nagai, K. Terada, G. Watanabe et al., "Differentiation of liver epithelial (stem-like) cells into hepatocytes induced by coculture with hepatic stellate cells," Biochemical and Biophysical Research Communications, vol. 293, no. 5, pp. 1420-1425, 2002.

[82] V. Jodon de Villeroché and D. Brouty-Boyé, "Establishment and characterization of atypical fibroblasts from human adult 
liver contributing to hepatocyte cord-like arrangement," Cell Biology International, vol. 32, no. 6, pp. 605-614, 2008.

[83] L. Libbrecht, D. Cassiman, V. Desmet, and T. Roskams, "The correlation between portal myofibroblasts and development of intrahepatic bile ducts and arterial branches in human liver," Liver, vol. 22, no. 3, pp. 252-258, 2002.

[84] T. Kinoshita, T. Sekiguchi, M. J. Xu et al., "Hepatic differentiation induced by oncostatin $\mathrm{M}$ attenuates fetal liver hematopoiesis," Proceedings of the National Academy of Sciences of the United States of America, vol. 96, no. 13, pp. 7265$7270,1999$. 

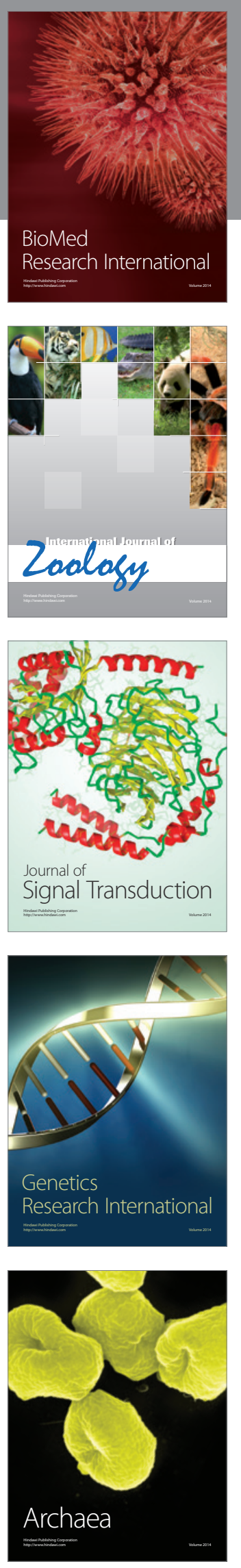
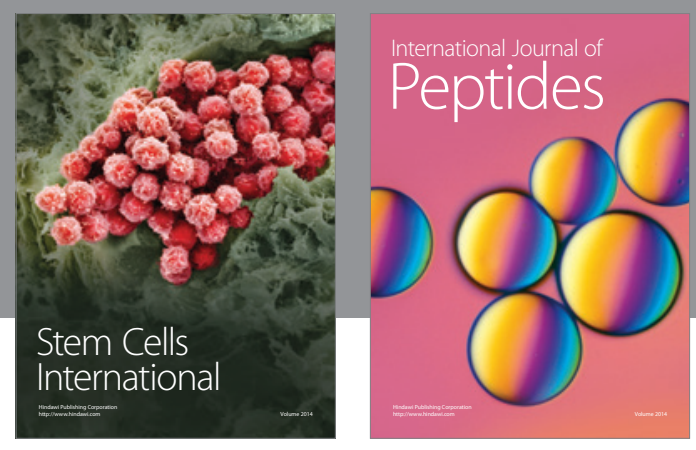

Submit your manuscripts at

http://www.hindawi.com
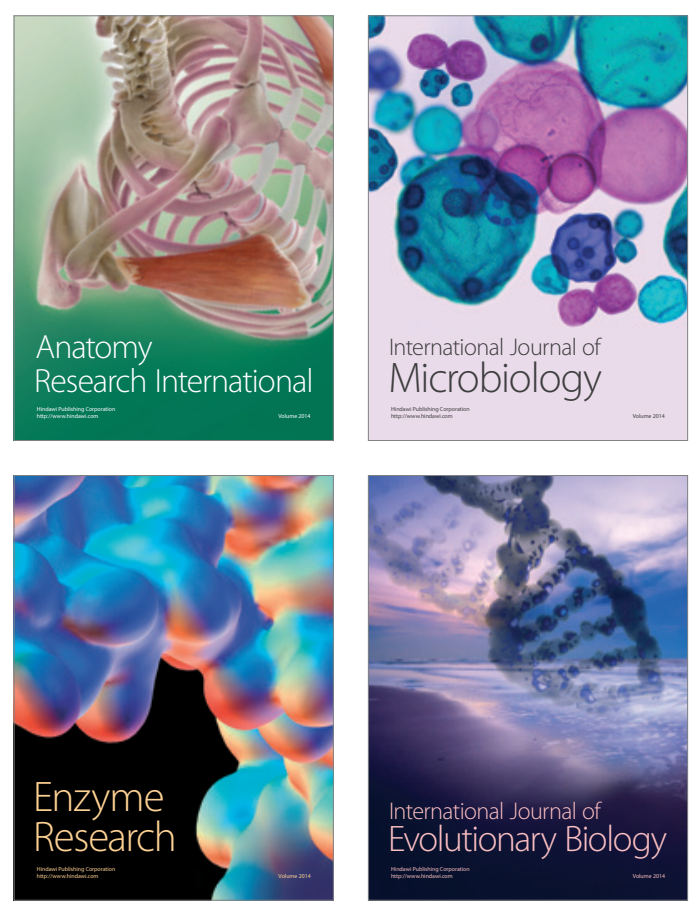
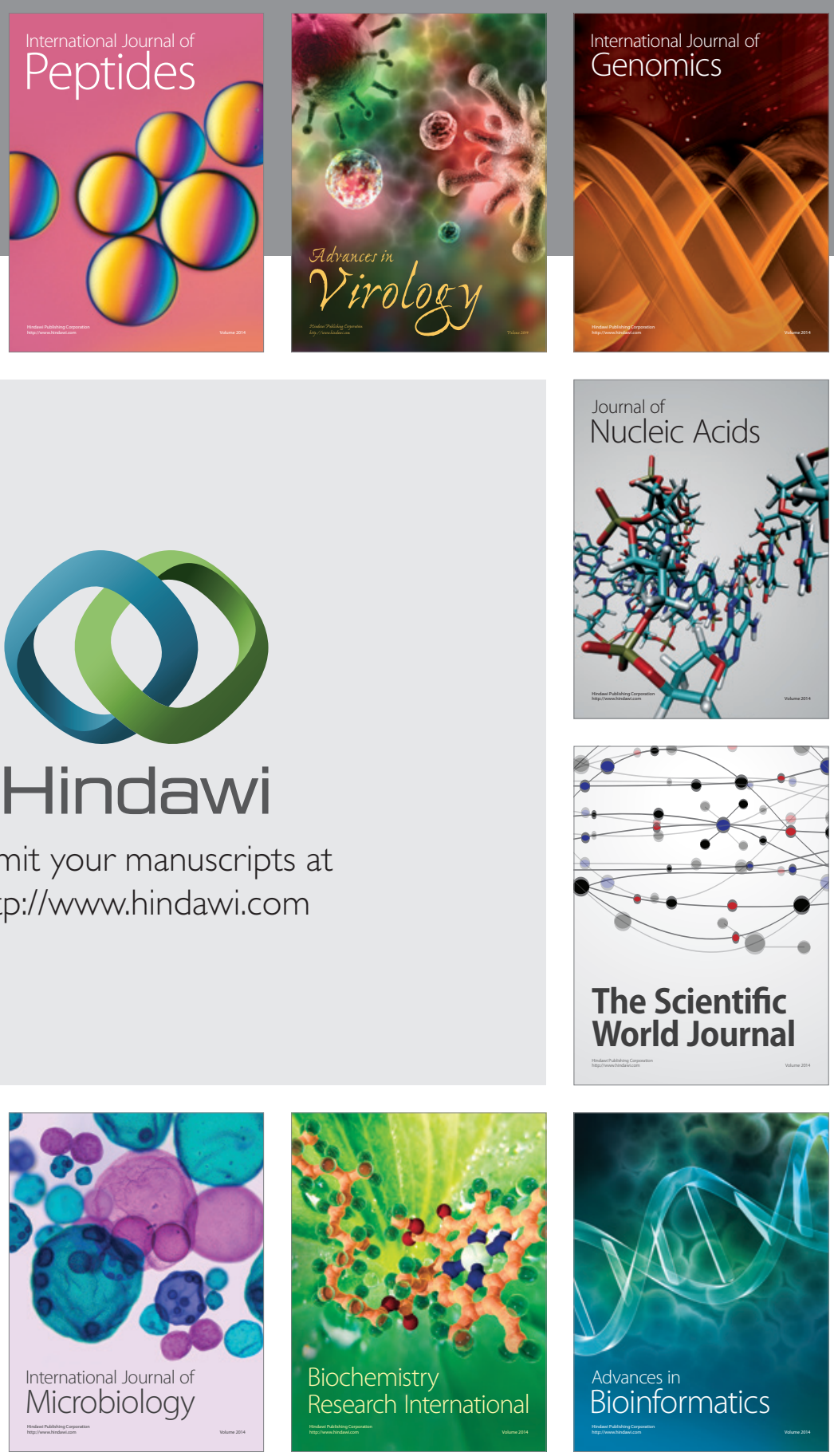

The Scientific World Journal
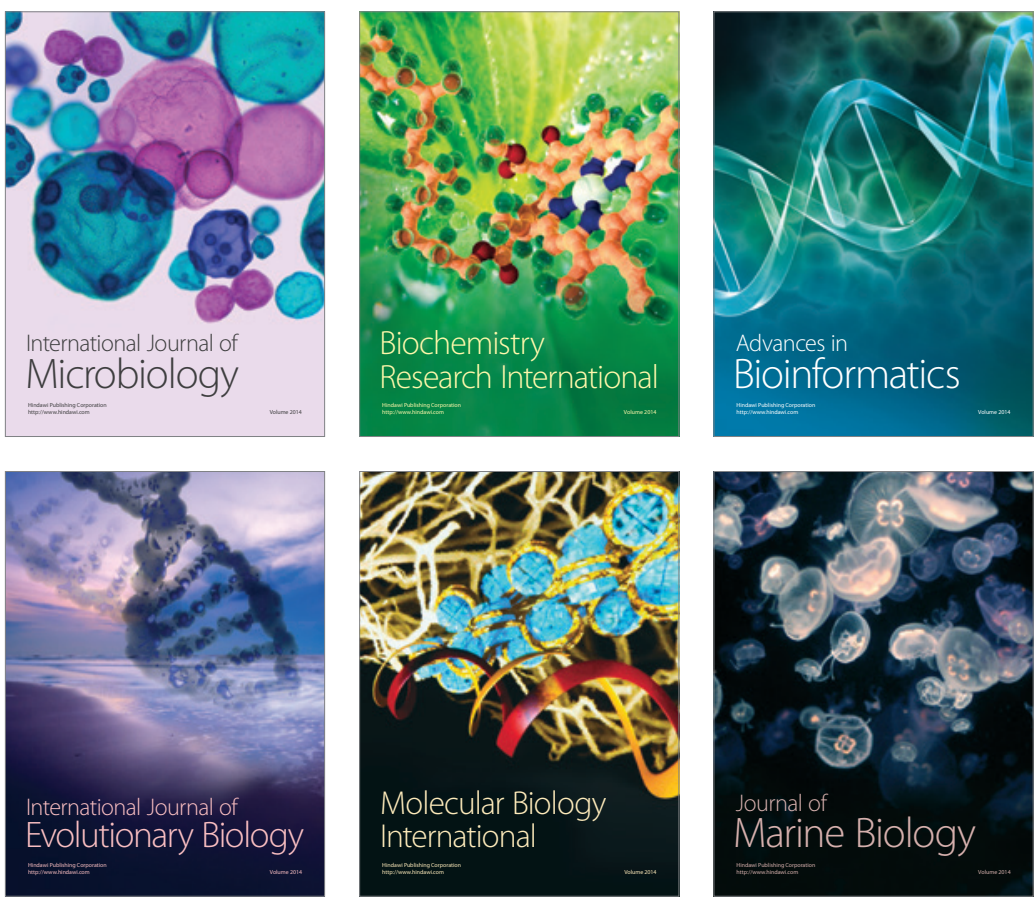